\title{
A governamentalização do Estado contemporâneo: uma cartografia dos mecanismos estatais de controle ${ }^{1}$
}

\author{
LUIZ FELIPE ROCHA BENITES*
}

Tentar pensar o Estado é expor-se a assumir um pensamento de Estado, a aplicar ao Estado categorias de pensamento produzidas e garantidas pelo Estado e, portanto, a não compreender a verdade mais fundamental do Estado (BOURDIEU, 1996, p. 91).

\section{Introdução}

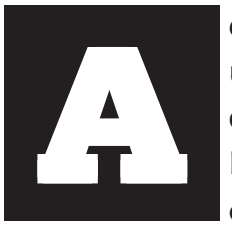

dúvida radical quanto aos riscos de uma análise sobre o universo estatal, anunciada por Pierre Bourdieu, mais do que nunca se mostra pertinente na contemporaneidade. Problematizar esta categoria canônica do pensamento social é investir em um território cuja produção discursiva é geralmente dominada por enunciados imersos na construção da sua própria continuidade.

O debate institucional, político ou acadêmico sobre o tamanho, papel ou capacidade de investimento do Estado, os impactos da "Globalização" sobre suas estruturas administrativas ou sobre a eficiência de suas políticas estão imersos em um jogo no qual a reflexividade crítica sobre os processos de dominação e sujeição freqüentemente é deixada de lado. Desta forma,

* Mestre em Sociologia (PPGS/UFRGS) e Professor do Centro Universitário Franciscano (UNIFRA) em Santa Maria, RS. 1 Este artigo é uma versão modificada do capítulo teórico da minha dissertação de mestrado, defendida junto ao PPGS/UFRGS. 
buscando não assumir o "pensamento de Estado", evitarei usar analiticamente, neste ensaio, referências a noções como "democracia", "monopólio da força", ou mesmo, "governança" e "eficiência", por já estarem estas comprometidas, no seu sentido e na sua lógica, com o debate que reproduz a própria idéia de Estado.

Sem a pretensão de construir uma reflexão de fôlego semelhante à do pensador francês, limito-me a assumir suas precauções na tentativa de construir uma breve cartografia que evidencie algumas linhas de força no cenário biopolítico em que a ação estatal se faz sentir no mundo contemporâneo. Penso que os processos de regulação e controle das populações, cuja emergência no século XIX foi identificada por Foucault, têm-se transformado, ao longo dos últimos anos, na direção da constituição da "Sociedade de Controle" de que nos fala Deleuze (1992). Acredito que as questões que permeiam as mutações dos regimes de poder na contemporaneidade e da própria produção do "bios" social, dizem respeito a algo que extrapole as fronteiras do que vulgarmente é atribuído ao domínio estatal. Consciente do devir da cartografia que estou traçando, levo comigo alguns princípios explicativos neste caminho cambiante em que me movo: a imanência, o nominalismo e a perspectiva relacional.

\section{Primeiros passos de um itinerário}

A primeira ruptura com o "pensamento de Estado" é assumir que as mudanças no universo estatal não são redutíveis a processos produzidos unicamente no seu próprio domínio. Aliás, o Estado, enquanto entidade, essência ou sujeito, não passa de uma ficção. No entanto, é preciso seguir um itinerário, um caminho de apresentação de certas noções necessárias para a produção de uma análise do cenário contemporâneo das relações de poder na qual o Estado seja tomado em precárias e conflituosas táticas governamentais, ainda que estas estejam assentadas em estruturas administrativas relativamente fixas ou permanentes. 
O caminho proposto começa com um discernimento: certas categorias de pensamento como o poder e o Estado costumam estar intimamente associadas, nos discursos produzidos pelas ciências sociais, fazendo com que, em certos casos, reduza-se a primeira a uma propriedade da segunda. Talvez, antes de ajustarmos o sentido da idéia de "Estado", seja necessário apresentar a noção que utilizaremos de poder. Tal noção se encontra nesta precaução metodológica enunciada por Foucault:

(...) não tomar o poder como um fenômeno de dominação maciço e homogêneo de um indivíduo sobre outros, ... de uma classe sobre outras; mas ter bem presente que o poder. ..não é algo que se possa dividir entre aqueles que o possuem e o detêm exclusivamente e aqueles que não o possuem e lhe são submetidos. $O$ poder deve ser analisado como algo que circula,...como algo que só funciona em cadeia.. ..O poder funciona e se exerce em rede. Nas suas malhas os indivíduos não só circulam mas estão sempre em posição de exercer e de sofrer sua ação. .. são sempre centros de transmissão. Em outros termos, o poder não se aplica aos indivíduos, passa por eles (FOUCAULT, 2000, p. 183).

Segundo esta definição, o poder se encontra esparso na sociedade, permeando todas as relações, sem, no entanto, ser apropriado unicamente por um indivíduo ou grupo. Assim, conforme Foucault (1995), uma reflexão crítica sobre o poder, que busque dar conta da sua complexidade, deve deslocar o seu interesse para além de perguntas como "o que é?", "de onde vem?", "como se manifesta?" para uma indagação do tipo "como se exerce?". Tal deslocamento implica assumir que o poder só existe em ato, só existe enquanto ação de uns sobre outros, ainda que, como afirma o autor, "se inscreva num campo de possibilidade esparso que se apoia sobre estruturas permanentes" (FOUCAULT, op. cit., p. 242). Isso significa que não há o "poder" de uma instituição estatal, mas práticas estratégicas de poder que animam tal instituição. 
O que está colocado em jogo são as relações entre os indivíduos ou grupos e, portanto, o objeto da análise são as relações de poder e não, o poder. Temos, então, o estabelecimento de um jogo complexo no qual a liberdade surge como uma condição de existência do poder. É necessário que haja liberdade para que o poder possa ser exercido:

O poder só se exerce sobre "sujeitos livres", enquanto "livres" - entendo por isso sujeitos individuais ou coletivos que têm diante de si um campo de possibilidade onde diversas condutas, diversas reações e diversos modos de comportamento podem acontecer. Não há relação de poder onde as determinações estão saturadas - a escravidão não é uma relação de poder, pois o homem está acorrentado (trata-se de uma relação física de coação) - mas quando ele pode se deslocar e, no limite, escapar (id., ibid., p. 244).

Se, então, é a forma da ação sobre a ação dos outros que define o exercício do poder, é o governo dos homens pelos homens que caracteriza o seu elemento mais importante. Governar significa "estruturar o eventual campo de ação dos outros" (id., ibid., p. 244). A prática governamental é que dá sentido a qualquer aparelho administrativo estatal. Contudo, devese salientar que a problemática governamental surge a partir de várias modalidades de intervenção. Somente então, ela será investida no campo estatal em um movimento que levará à "governamentalização" do Estado.

\section{A emergência da problemática do governamento}

Antes de seguirmos adiante é momento de refinarmos um conceito que é fundamental. Seguindo a sugestão de Veiga-Neto (2002), optamos por substituir, a partir desta parte do texto, o termo "governo" utilizado nas traduções brasileiras da obra foucaultiana para traduzir gouvernement, por "governamento". Tal substituição não busca um sentido final ou verdadeiro 
para a palavra originária do francês, mas conferir um maior rigor ao conceito, de maneira a distingui-lo do sentido vulgarmente atribuído à expressão "governo" (instâncias administrativas centrais, como Governo municipal ou estadual, etc.). Sendo assim, quando nos referirmos a "governamento", estaremos remetendo-nos à ação de governar. Tal ação, irredutível a uma prática transcendental do Estado, situa-se no plano de imanência de uma rede de poder que se orienta sobre diversos objetos a serem governamentalizados.

Foi no século XVI, na Europa, que o problema do governamento emergiu sob diversos aspectos: o governamento de si mesmo, em uma reatualização do estoicismo; o governamento das condutas e das almas empreendido pela pastoral cristã; o governamento das crianças estudado pelos pedagogos e o problema do governamento dos Estados pelos príncipes. É a partir desta multiplicidade de problemas que começa a se gestar um tipo de racionalidade específica, pautada na organização e controle das condutas que têm por alvo a população.

Essa nova racionalidade ganha corpo na constituição de um novo saber. A "arte de governar" o Estado se constituiu nesse saber específico, opondo-se à literatura maquiavélica, concentrada na habilidade de conservar o principado. Por conseguinte, a "arte de governar", constituída a partir de várias modalidades de governamento (de si mesmo, da família, empresa, etc.) marca uma distinção com a singularidade do príncipe maquiavélico, único em seu principado. Isto é, a doutrina do príncipe apresenta uma descontinuidade entre o poder deste e os outros poderes, enquanto a "arte de governar" estabelece uma continuidade (ascendente e descendente) entre as tipologias de poder. Outro aspecto importante acerca da "arte de governar" foi a introdução da economia na gestão estatal, "isto é, a maneira de gerir corretamente os indivíduos, os bens, a riqueza no interior da família" (FOUCAULT, 2000, p. 281). 
A gestão, enquanto princípio econômico - em seu sentido originário, articulado à esfera doméstica - tornou-se o traço fundamental deste novo saber. Tal teoria esteve intimamente ligada ao desenvolvimento dos apareIhos administrativos da monarquia territorial que originaram os aparelhos de governamento durante o século XVI. No início do século XVII, a teoria da arte de governar esteve dedicada a conhecer os elementos constitutivos e as possíveis dimensões do Estado, isto é, o saber, então denominado estatística, ou em outras palavras, a ciência do Estado. Finalmente, essa teoria, segundo Foucault, esteve estreitamente associada ao mercantilismo e ao cameralismo.

A primeira cristalização da "arte de governar" se organizou ao redor do tema da Razão de Estado. Foi nos corpos de doutrina que a Razão de Estado se formou, articulando-se com a teoria da Polícia. A doutrina da Razão de Estado buscava definir em que medida os princípios e métodos do governo estatal eram diferentes de como, por exemplo, Deus governava o mundo, o pai, a sua família, ou mesmo, um superior, sua comunidade. Por outro lado, a doutrina da Polícia tentava definir a natureza dos objetos da atividade racional do Estado, a natureza dos objetivos que ele persegue, bem como a forma geral dos instrumentos que ele emprega. Percebe-se, então que "arte de governar" é racional e leva a refletir sobre o que é governado: o Estado aí, revela-se o aspecto fundamental da Razão de Estado: reforçar o próprio Estado.

De forma sintética, Foucault nos apresenta o que ele definiu como história da governamentalidade, entendendo este conceito como:

1- o conjunto constituído pelas instituições, procedimentos, análises e reflexões, cálculos e táticas que permitem exercer esta forma (...) de poder, que tem por alvo a população, por forma principal de saber a economia política e por instrumentos essenciais os dispositivos de segurança. 
2- a tendência que em todo o Ocidente conduziu (...) à preeminência deste tipo de poder, que se pode chamar governo, sobre todos os outros - soberania, disciplina, etc. - e levou ao desenvolvimento de uma série de aparelhos específicos de governo e de um conjunto de saberes.

3- o resultado do processo do qual o Estado de justiça da Idade Média, que se tornou nos séc. XV e XVI Estado Administrativo, foi pouco a pouco governamentalizado (id., ibid., p. 291-292).

A problemática do governamento não se restringe ao universo estatal, mas ganhou nele uma peculiaridade que caracteriza determinados aspectos modernos das relações de poder. Ciente desta especificidade, o autor expõe que, desde o século XVIII, a sociedade ocidental vive o fenômeno da governamentalidade, mostrando que, ao contrário da estatização da sociedade, o que se observou foi a governamentalização do Estado, fenômeno que permitiu a sua sobrevivência e o seu fortalecimento. Portanto, a compreensão do Estado deve partir da observação das táticas gerais da governamentalidade.

\section{O Estado governamentalizado}

Foucault (1990), em uma perspectiva nominalista, coloca o Estado como uma instância sob a forma política de um poder centralizado e centralizador, cujas técnicas estão orientadas para os indivíduos e destinadas a governá-los. Autores como Weber (1969), Bourdieu (1996) e Elias (1993) também apontam, ao seu modo, as características centralizadas e centralizadoras do campo estatal, entretanto a leitura foucaultiana da relação entre Estado, poder e governamento apresenta uma diferença importante. Ela pode ser entendida no sentido de que: 
(...) o Estado vai se determinando pelas táticas de governo em seu exercício. Em outras palavras, o governo organiza a relação de poder de modo a produzir um processo de estatização. Por outro lado, o Estado enquanto ilusão é um referente importante para o processo de centralização e hierarquização (não redução) dos poderes (MACEDO JR, 1990, P. 165).

A razão da força do Estado se deve ao fato de ter se ele tornado um poderoso mecanismo de individualização e de totalização (FOUCAULT, 1995). A individualização produzida pelo Estado ocorre por conta da integração, sob uma nova forma, a de uma antiga tecnologia de poder originária das instituições cristãs: o poder pastoral. Entre as características deste tipo de poder se encontram entre outras: a) o objetivo de garantir a salvação individual no outro mundo; b) o preparo para se sacrificar pela vida e salvação do rebanho; c) cuida de cada indivíduo em particular e não apenas da comunidade como um todo; d) exerce-se a partir do conhecimento da mente das pessoas, da revelação de seus segredos (id., Ibid., p. 237).

Sob a égide estatal, o poder pastoral foi redimensionado em suas caracterizações. O objetivo agora é a salvação neste mundo. A salvação assume novos significados: "saúde, bem-estar (...), segurança, proteção contra acidentes" (id., ibid., p. 238). Há, também, o reforço das estruturas de administração desse poder. Elas vão desde os próprios aparelhos estatais, passando pelas instituições filantrópicas e médicas, até as estruturas mais antigas, como a família. A diversidade de objetivos e agentes do pastorado necessitavam desenvolver novos saberes que se organizaram a partir de um eixo global e quantitativo relativo à população (a estatística, por exemplo) e outro eixo analítico centrado no indivíduo (como a psiquiatria).

No que diz respeito à totalização, a "gestão das forças estatais", tema que se desenvolve a partir do fim do século XVII, inscreve-se nos quadros gerais de uma forma política emergente: a "biopolítica". Segundo Foucault, a "biopolítica" corresponderia "a maneira pela qual se tentou desde o século 
XVIII, racionalizar os problemas propostos à prática governamental, pelos fenômenos próprios a um conjunto de seres vivos constituídos em população: saúde, higiene, natalidade, raças. .." (FOUCAULT, 1997, p. 89). Surgem, então, novos procedimentos para além dos mecanismos individualizantes. A tecnologia nascente buscava, pelo contrário, num movimento de totalização, a regulação dos fatos aleatórios que acometem uma determinada população (FOUCAULT, 1999, p. 293).

Além dos problemas relativos à reprodução, natalidade e morbidade, o campo de intervenção biopolítico se estende a outros fenômenos tanto "universais" como "acidentais":

Será o problema muito importante, já no início do século XIX (na hora da industrialização), da velhice, do indivíduo que cai, em conseqüência, para fora do campo de capacidade, de atividade. E, de outra parte, os acidentes, as enfermidades, as anomalias diversas. E é em relação a estes fenômenos que essa biopolítica vai introduzir não somente instituições de assistência (que existem faz muito tempo), mas mecanismos muito mais sutis, economicamente muito mais racionais do que a grande assistência, a um só tempo maciça e lacunar, que era essencialmente vinculada à Igreja. Vamos ter mecanismos mais sutis, mais racionais, de seguros, de poupança individual e coletiva, de seguridade, etc. (id., ibid., p. 291).

Eis a gênese das instituições estatais de proteção social. Os aparelhos administrativos de proteção social, vinculados ao Estado, são o suporte da realização das políticas sociais, que segundo Jobert (1985, p. 301), podem ser entendidas como "a regulação política da produção dos homens". Conforme o autor, as políticas sanitárias e sociais possuem três dimensões distintas: 1) a produção dos homens como espécie biológica (biopolítica da população); 2) a produção dos homens como produtores, isto é, força de trabalho; 3) a produção dos homens como membros da comunidade política, isto é, como cidadãos. 
O nascimento da "biopolítica" marca a emergência de outros mecanismos, mais globais, de busca de equilíbrio, de regularidade, enfim, mecanismos de gestão da vida. O que se procura assegurar ao "homem-espécie" não seria uma disciplina, mas uma regulamentação. Estamos diante de um poder distinto da soberania sobre a vida ("fazer morrer" e "deixar viver"). A passagem do homem-corpo ao homem-espécie é um sintoma de que o biopoder consolida o direito político de "fazer viver" e "deixar morrer" (FOUCAULT, 1999, p. 287).

\section{O controle sobre os agentes estatais}

Mesmo reconhecendo suas características centralizadas e centralizadoras, não deve imaginar-se o Estado como uma unidade homogênea ou como um quase "sujeito". A multiplicidade de agentes sociais, aparelhos administrativos, saberes, técnicas e estratégias que compõem o universo burocrático demonstram a heterogeneidade mesma das formas de poder que circulam e atravessam entre as fronteiras estatais.

Entre os componentes deste universo heterogêneo encontra-se a formação de uma classe de profissionais encarregados de gerir as coisas próprias do Estado: os burocratas. Weber (1969) havia entendido o surgimento da burocracia como produto evolutivo da crescente racionalização da vida social nas sociedades ocidentais. Instrumento para o exercício da dominação racional ou legal, a organização burocrática baseia-se em normas que devem ser aplicadas a todo o grupamento social, afastando, assim, os elementos sensíveis (amor, ódio, etc.) e as influências tradicionais (riqueza, vínculos de amizade e parentesco, etc.) da gestão dos negócios. Entre as características da burocracia poderiam ser encontradas a hierarquia na organização, a impessoalidade no relacionamento, a especialização de funções, o recrutamento por meio de critérios objetivos, a resolução técnica dos problemas. 
Essa caracterização, segundo o tipo ideal weberiano, tem sido repensada por vários autores. Neste sentido, minha opção é trabalhar com abordagens que busquem articular as relações entre saber e poder na compreensão do espaço burocrático. A contribuição de Bourdieu, Christin e Will (2000) mostra-se pertinente para este propósito. Conforme estes autores, uma das atividades fundamentais das modernas burocracias é o trabalho de vigiar e avaliar os seus próprios agentes, bem como suas próprias ações. Logo, o controle burocrático não é um limite à burocracia, antes disso, ele funda a própria burocracia.

O controle burocrático se faz por uma série de mecanismos que não se dissociam de um tipo específico de saber que passa a se produzir no interior do universo estatal. O conhecimento produzido no campo burocrático foi denominado por Bourdieu, Christin e Will (2000) de "ciências do Estado" (sciences d'État). Trata-se de ciências práticas constituídas a partir dos saberes burocráticos materializados nos organogramas, regulamentos internos, memorandos, próprios de um trabalho de invenção de rotinas e procedimentos que garantem a própria continuidade do Estado.

É interessante notar que o surgimento de uma burocracia - e o conseqüente desenvolvimento de um saber que lhe é específico - associada à expansão dos aparelhos administrativos operou, em certas esferas, conforme Genet (1997), um efeito de "despersonalização" do poder do soberano. Tal efeito se difunde, à medida que o campo burocrático se autonomiza, criando critérios próprios de seleção de pessoal, bem como rotinas e procedimentos marcados pela ruptura com as lógicas personificadas que caracterizavam o domínio patrimonial.

Embora esses autores se refiram, constantemente, às modernas burocracias, a preocupação com a qualificação e procedimentos de controle institucional da ação dos indivíduos não é um privilégio das sociedades ocidentais modernas. O artigo de Lamouroux (2000) sobre a relação da constituição de uma "ciência do Estado" com a formação de uma classe de 
profissionais da "coisa pública", na China dos séculos VIII a XI, evidencia a preocupação da dinastia Song com a avaliação daqueles que tinham a pretensão de servir ao soberano. Dando atenção aos fatores políticos da elaboração dos procedimentos técnicos do aparelho administrativo, o autor vai mostrar que os mecanismos que conformam a missão e o aspecto performativo do Estado Chinês estavam indissociados dos instrumentos de gestão interna da função pública.

Analisando o caso da China pré-moderna, o autor demonstra que, durante o império da Dinastia Song, houve o interesse do soberano em consolidar, no aparelho administrativo, um quadro de funcionários civis encarregados da administração financeira. A formação desse grupo foi acompanhada da elaboração de um sistema de gestão de carreiras que dependia de avaliações regulares do soberano. Estas formas de avaliação estavam articuladas à vigilância das atividades dos funcionários, por meio de procedimentos formalizados (relatórios, controle de rubricas, etc.) cuja lógica de controle, baseada em princípios meritocráticos, era distinta de outras estabelecidas por elos pessoais. Foi desenvolvido, então, um processo de estandardização dos critérios de avaliação em dossiês sobre o trabalho dos funcionários cujo controle da atividade laboral se convertia também em controle do fisco. Logo, a gestão da carreira funcional estava articulada à capacidade da administração fiscal, graças à sua organização interna de limitar as práticas delituosas, fornecendo ao soberano instrumentos objetivos para sua apreciação.

Estudos como o do caso chinês demonstram como, no setor estatal, constituíram-se mecanismos pelos quais se engendraram saberes e práticas destinados à seleção e controle daqueles homens cujo trabalho é a regulação e controle dos demais indivíduos da sociedade. O conjunto de rotinas e procedimentos burocráticos aos quais Max Weber associou a dominação burocrática não se aplicam somente à população, mas submete os próprios funcionários estatais. Adotando a perspectiva foucaultiana, pode-se afirmar 
que, para governar a população, é preciso que o Estado governe-se a si próprio. Logo, a produção das "ciências de Estado", bem como todas as táticas de controle do corpo funcional está imersa no complexo jogo de governamentalização do Estado.

A realidade de países periféricos - como o Brasil e outros da América Latina, por exemplo - apresenta algumas especificidades no campo estatal. A história da burocracia nesses países revela uma tensão entre distintas lógicas que permeiam os discursos e práticas no espaço estatal, ${ }^{2}$ afastandose bastante da caracterização da burocracia inscrita no "tipo ideal" weberiano. Para compreender esta tensão, seria útil recorrer à noção de "hibridação" utilizada por Badie e Hermet (1993). "Hibridação" diz respeito ao fenômeno de coexistência e, muita vezes, do confronto de diferentes lógicas ou racionalidades face à importação, geralmente parcial, de certos bens políticos pelas elites conservadoras ou revolucionárias de sociedades periféricas, os quais foram produzidos em condições sociais distintas daquelas apresentadas nos universos importadores.

Os aparelhos administrativos estatal nesses países são um produto da importação de modelos e concepções de Estado dos países centrais. Não é difícil encontrar os efeitos deste processo ora nos conflitos, ora nas complementaridades que se estabelecem entre "legalismo" e transgressão de normas, sistemas meritocráticos (concurso público, etc.) e apadrinhamentos, impessoalidade e formas de apropriação privadas do bem público (patrimonialismo, clientelismo, corrupção, etc.) no seio das referidas burocracias.

Diante do exposto, verifica-se que as atividades desempenhadas pelos burocratas, isto é, pelos trabalhadores do ou no Estado (as terceirizações e subcontratações também são realidades na esfera estatal) são cruciais para a conformação das práticas governamentais conduzidas pelo Estado, inclusive nos países periféricos. $\mathrm{O}$ trabalho burocrático, popularmente entendido como 
do "serviço público", pressupõe - embora não se limite - um conjunto de atividades de enquadramento de indivíduos em um sistema normativo-legal, regulando suas obrigações e o seu acesso ao serviços oferecidos pelos apareIhos administrativos do Estado. Esse trabalho, que invariavelmente implica um processo de reconhecimento de direitos e regulação de deveres, é exercido por meio de um conjunto de rotinas e procedimentos ritualizados, realizados diariamente por um corpo de funcionários.

Esse trabalho se constitui em um elemento central para a compreensão do exercício do governamento. O trabalho burocrático, assim como as demais atividades do setor de serviços, inclusive os que não se encontram na esfera estatal, não produz bens materiais (pelo menos diretamente); contudo não deixa de envolver um processo de produção. O produto deste tipo de trabalho se encontra na ordem do simbólico, daquilo que envolve a linguagem, a comunicação, os afetos, que produz bens não-tangíveis (serviços, direitos, afetividades), enfim que produz bens "imateriais". Tais atividades se referem propriamente ao "trabalho material", de que falam Hardt e Negri (2001) e Lazzarato e Negri (2001).

\section{O trabalho burocrático como dispositivo}

A produção de direitos envolve, por um lado, lutas sociais para definição do reconhecimento de certas prerrogativas a distintos grupos sociais, bem como um conjunto de procedimentos ritualísticos que conduzem ao sancionamento jurídico de tais direitos. Por outro lado, o reconhecimento das prerrogativas para legitimar o acesso aos serviços destinados à população, às vezes dividida em segmentos, é feito através do "trabalho imaterial" dos funcionários públicos. Esse trabalho, entretanto, é modelado e modulado por certos mecanismos da racionalidade reguladora estatal.

O trabalho genealógico de Foucault sobre os mecanismos disciplinares é deveras útil na compreensão da modelação do sujeito moderno. Para 
entender como a disciplina se converteu em um mecanismo eficiente no molde dos sujeitos, é necessário recorrer à noção de "dispositivo". Nas palavras do próprio autor:

Através deste termo tento demarcar em primeiro lugar, um conjunto decididamente heterogêneo que engloba discursos, instituições, organizações arquitetônicas, decisões regulamentares, leis, medidas administrativas (...) O dispositivo é a rede que se pode estabelecer entre esses elementos (...) Em segundo lugar, (...) entre estes elementos, discursivos ou não, existe um tipo de jogo, ou seja, mudanças de posição, modificações de funções, que também podem ser muito diferentes. Em terceiro lugar, (...) o dispositivo tem (...) uma função estratégica importante (FOUCAULT, 2000, p. 244).

Um "dispositivo", de modo operacional, pode ser entendido como um "agenciamento concreto" que efetua uma máquina abstrata, um diagrama:

O diagrama, ou a máquina abstrata, é o mapa das relações de força, mapa de densidade, de intensidade, que procede por ligações primárias não-localizáveis e que passa a instante por todos os pontos, (...) a máquina abstrata é como a causa dos agenciamentos concretos que efetuam suas relações; e essas relações de força passam, "não por cima", mas pelo próprio tecido dos agenciamentos que produzem (DELEUZE, 1988, p. 46).

O dispositivo também apresenta uma bifurcação: "(...) todo dispositivo é um mingau que mistura o visível e o enunciável" (id., ibid., p. 48). Assumindo a relação imanente entre saber e poder exposta na obra "Vigiar e Punir" de Foucault, Deleuze salienta que, na passagem do visível ao enunciável, e vice-versa, há a ação transversal de uma relação de forças possibilitada, na análise do diagrama disciplinar, pelo "encontro das visibilidades da prisão com os enunciados do direito penal" (id., ibid., p. 48). 
Assim, a dimensão produtiva das relações de saber/poder é fabricada por intermédio da operação tecnológica de uma potente maquinaria (abstrata e concreta/material). Isto implica que:

(...) as máquinas são sociais antes de serem técnicas. Há uma tecnologia humana antes de haver uma tecnologia material. Os efeitos desta atingem, é certo, todo o campo social; mas para que ela seja possível, é preciso que os instrumentos, é preciso que as máquinas materiais tenham sido primeiramente selecionadas por um diagrama, assumidas por um agenciamento. (...) por exemplo, a prisão pode ser existência apenas marginal na sociedade de soberania (as lettres de cachet), ela só existe como dispositivo quando um novo diagrama, o diagrama disciplinar, a faz ultrapassar "o limiar tecnológico" (id., ibid., p. 49).

É necessário, ainda, compreender que o visível e o enunciável se constituem em dimensões "estratificadas", isto é, são "formações históricas, positividades, empiricidades" (id., ibid., p. 57). Há ainda outras duas dimensões a serem consideradas no desdobramento da maquinaria do saber/poder. Uma é o das linhas de força, ou o "lado de fora", ou ainda, o "não estratificado". O "estratificado" pode ser facilmente associado à produção do saber, o "não estratificado", por sua vez, encontra-se no domínio das "relações de força", das "relações de poder" (id., ibid., p. 78). As linhas de força atuam, como já foi dito, no encontro do visível e do enunciável, mas o poder não se refere a formas ou funções formalizadas:

Com efeito, ele não passa por formas, mas por pontos, pontos singulares, que marcam a cada vez, a aplicação de uma força, a ação ou reação de uma força em relações às outras (...) É a instabilidade das relações de poder que define um meio estratégico ou não estratificado (id., ibid., p. 81). 
Por fim, a dimensão restante, e não menos importante, é a do "lado de dentro", ou da subjetividade. Deleuze assume a subjetividade na reflexão foucaultiana como "dobra", isto é, como uma membrana, uma prega que, ao vergar às forças externas, produz a interioridade (DELEUZE, 1988). Tal concepção rompe com a tradicional oposição objetivo-subjetivo, tão enraizada nas ciências sociais. Não há simplesmente interiorização da externalidade, mas em uma analogia à fisiologia, movimentos peristálticos nos quais o lado de fora é vergado para dentro mas também é coextensivo.

Propomos assumir o trabalho burocrático como um dispositivo cujo diagrama a ser efetuado exporei adiante. $O$ trabalho enquanto agenciamento concreto não produz somente a objetivação do trabalhador (por meio de zonas de enunciação e visibilidade e de correlações de força precárias e instáveis), mas também atua ao moldar e modular formas de subjetivação, ao produzir uma "dobra" que implica um modo de sujeição desse trabalhador. Assim, creio que há um nexo entre o controle e regulação da vida dos indivíduos (o "governamento dos outros") na atividade dos trabalhadores no serviço público e as práticas exercidas por esses mesmos trabalhadores sobre si (o "governamento de si') como forma de prender o trabalhador à sua própria identidade.

Como demonstrou Lamoroux (2000), no estudo do Estado chinês durante o período da dinastia Song, os sistemas de gestão do corpo de funcionários não se dissociam da missão e do aspecto performativo do Estado. Fica claro, então, que entre as correlações de força existentes no espaço da burocracia, o exercício do "governo de si" é condição para o exercício do "governo dos outros". Subjetivação, neste caso, aproxima-se, portanto, da sujeição. Sujeição ao conjunto de normas e demais elementos heterogêneos que fazem do trabalho burocrático, por um lado, um dispositivo de segurança estratégico para o exercício do governamento da população e, por outro lado, um dispositivo de subjetivação, estratégico na produção do sujeito moralmente "apegado" à sua identidade de trabalhador no serviço público. 


\section{As malhas da sociedade de controle}

Deleuze (1992) buscou levar adiante aspectos latentes na reflexão de Foucault, para escrever nas suas entrelinhas. Assim como a "sociedade disciplinar" sucedeu à "sociedade de soberania" no século XVIII, na análise foucaultiana, Deleuze situa a experiência de vida ocidental neste século em uma transição, desde o fim da II guerra, dessa "sociedade disciplinar" para uma "sociedade de controle". Essa transição marca a constituição de novos dispositivos de poder que se disseminam e se sofisticam com enorme rapidez. A referida transformação não significa a eliminação total de elementos de um modelo de sociedade na passagem para outro. Os novos mecanismos dessa "sociedade de controle" engendram novas produções, simultaneamente materiais e subjetivas, que perpassam o universo estatal, o mundo do trabalho e a esfera privada. Vejamos suas principais características.

O advento da "sociedade de controle" marca a mudança de uma forma de organização societal marcada por técnicas e saberes que forjaram o homem confinado, individualizado, produtor descontínuo de energia, para uma forma na qual o controle é de curto prazo, contínuo e ilimitado, uma sociedade de comunicação rápida e instantânea. Segundo Deleuze (op. cit., p. 221) a antiga fábrica do disciplinamento, do confinamento dá lugar à empresa do controle contínuo e difuso, da formação permanente. Os confinamentos se constituíam em "moldes", já os controles são "modulações", isto é, uma moldagem que muda a todo instante, que vai de um determinado ponto a outro.

O poder, nas sociedades disciplinares, era totalizante (ou massificante) e individualizante. Por um lado, transformava aqueles sobre os quais exercia sua força em um corpo único (a população) e, por outro, moldava individualmente cada membro da população. Portanto:

As sociedades disciplinares têm dois pólos: a assinatura que indica o indivíduo, e o número de matrícula que indica sua posição numa massa. (...) Nas sociedades de controle, ao contrário, o essencial não é mais a assina- 
tura e nem o número, mas uma cifra: a cifra é uma senha (...) A linguagem numérica do controle é feita de cifras, que marcam o acesso à informação, ou a rejeição. Os indivíduos tornam-se "dividuais", divisíveis, e as massas tornam-se amostras, dados, mercados ou "bancos" (id., ibid., p. 222).

Curto prazo, regulação permanente, rapidez de comunicação, modulações, senhas são elementos desta nova configuração de sociedade mapeada por Deleuze. Na interpretação de Hardt (2000), o desenho traçado pelo pensador francês necessita ser correlacionado a outros processos mais amplos que se vêm operando na sociedade contemporânea. Hardt, compartiIhando reflexões com Antonio Negri, apresenta dois importantes processos, a serem conectados à formação da "sociedade de controle":

(...) qualificamos o primeiro processo de enfraquecimento da sociedade civil, o que, assim como a passagem à sociedade de controle remete ao declínio das funções mediadoras das instituições sociais; com o segundo ocorre a passagem do Imperialismo, produzido inicialmente pelos Estados-Nação europeus, ao império, à nova ordem mundial, que se estende hoje em torno dos Estados Unidos, com as instituições transnacionais e o mercado mundial (Hardt, op. cit., p. 358).

Continuando esta reflexão, Hardt e Negri (2001) afirmam: não há mais um "fora" para o capitalismo, suas fronteiras não compreendem limites e se encontram em permanente expansão. A transcendência da soberania política moderna, alicerçada nos Estados-Nação, entra em conflito com a lógica operatória imanente do capitalismo. Nessa correlação de forças, a soberania acaba submetida à lógica imanente do capital. O Império é o nome dado à essa forma de soberania, ${ }^{3}$ que num movimento contrário ao

3 A noção de "Império" tornou-se alvo de diversas críticas, mas não me parece fértil para o objetivo do artigo reproduzi-las e discuti-las aqui. As características do Império com as quais trabalho, acredito serem pertinentes para situar a conjuntura mundial atual. Para acessar uma dessas leituras críticas ver Boron (2002). 
lugares, penetrando todos os espaços da existência.

O que potencializou essa expansão do capital foram justamente os mecanismos flexíveis, moduláveis, difusos que encarnam a "sociedade de controle" diagnosticada por Deleuze. A sugestão de Hardt (2000) é "que a forma social tomada por esse novo Império é a sociedade de controle mundial" (op. cit., p. 358).

Uma das implicações desta hipótese do autor é que:

A sociedade de controle (...) não se organiza em torno de um conflito central, mas em uma rede flexível de microconflitualidades. As contradições, na sociedade imperial, são múltiplas, e proliferam em todos os lugares. Os espaços dessa sociedade são impuros, híbridos (id., ibid., p. 371).

Diante do exposto, se torna preciso situar certas mudanças promovidas pelo "Império", principalmente no que diz respeito aos processos que levam a tendência à imanência da lógica capitalista ao universo estatal. Entendo que as reformas estatais, debatidas e implementadas na década de 90, inserem-se neste processo de constituição da "Sociedade Mundial de Controle" e fazem parte de uma agenda que atualiza o fenômeno da "governamentalidade", em um cenário assim descrito por Veiga-Neto:

O que está ocorrendo é uma reinscrição de técnicas e formas de saberes, competências, expertises, que são manejados por "expertos" e que são úteis tanto para a expansão das formas mais avançadas do capitalismo, quanto para o governo do Estado. Tal reinscrição consiste no deslocamento e na sutilização de técnicas de governo que visam fazer com que o Estado siga a lógica da empresa, pois transformar o Estado numa grande empresa é muito mais econômico - rápido, fácil, produtivo, lucrativo (VEIGA-NETO, 2000, p. 198). 
Cabe, neste caso, relembrarmos que: "toda sociedade tem o seu ou os seus diagramas" (DELEUZE, 1988, p.45). Se a sociedade disciplinar deu lugar à sociedade de controle, é possível pensar na transmutação de um diagrama disciplinar para um diagrama do controle. O diagrama que o dispositivo do trabalho burocrático efetua atualmente é o diagrama do controle. Isto significa que o trabalho no serviço público tem sido investido por novos e sutis mecanismos de controle, em uma tática que visa, ao renovar a regulação sobre os agentes do Estado, controlar e regular mais refinadamente a vida da população.

Segundo Hardt (1997), o Império possui três imperativos (integrar, diferenciar e gerenciar) que se aplicam ao modo de administrar a vida das populações. Aprofundando esta idéia junto com Negri (2001), ele sugere que na administração imperial, as "burocracias (e meios administrativos em geral) são consideradas não de acordo com a lógica linear de sua funcionalidade com relação aos objetivos mas de acordo com a lógica instrumental diferencial e múltipla" (op. cit., p. 362). Logo, o problema de gestão não se refere mais à unidade administrativa mas à sua multifuncionalidade. Por fim, uma última característica da regulação imperial diz respeito ao fato de a administração não estar orientada estrategicamente para realizar as lógicas imperiais, mas submete-se a elas, como condição para manter o seu exercício. Tal condição de exercício parece intimamente articulada à gradual incorporação da racionalidade empresarial capitalista.

A presença da racionalidade capitalista na transformação do Estado brasileiro está relacionada aos mecanismos de produção e difusão de conhecimentos e técnicas, pelo intermédio das estratégias internacionais dos técnicos políticos, de que falam Dezalay e Garth (2000). Segundo esses autores, "estratégia internacional" é um conceito "que se refere à forma pela qual os indivíduos usam capital internacional - títulos universitários, conhecimento técnico, contatos, recursos, prestígio e legitimidade obtida no exterior - para construir suas carreiras em seus países natais" (idem, p. 164). Este estudo vai 
além das abordagens que buscam as razões desse fenômeno, por um lado, apenas na imposição de programas de "ajuste estrutural" por organismos como o FMI ou o Banco Mundial ou, por outro lado, unicamente nas mudanças das "preferências das elites" por um Estado mais enxuto. A reforma do aparelho de Estado no Brasil defendida por técnicos políticos ${ }^{4}$ trouxe para o interior das estruturas administrativas estatais, por meio de um jogo estratégico de táticas de governamento, os saberes e técnicas consolidados do mundo empresarial capitalista.

A implementação de elementos de um "modelo de gestão gerencial", ao contrário do que defende Bresser Pereira (1998), apresenta um potencial de agregação às tradições da burocracia brasileira (seja de forma conflituosa ou complementar) e não de supressão das mesmas. A constituição híbrida dos aparelhos administrativos brasileiros diagnosticada por autores como Badie e Hermet (1993) é anterior ao próprio hibridismo do Império de que falam Hardt (1997) e Hardt e Negri (2001).

Certamente abre-se um vasto campo para investigações empíricas sobre as novas configurações híbridas na era imperial. Ciente dos perigos da construção de projeções neste cenário, arrisco-me a pensar que princípios reformistas tais como a autonomia gerencial sem mecanismos reais de controle por parte das populações pode reforçar certas tradições autoritárias do Estado brasileiro. Hoje, tais mecanismos de controle restringem-se (pelo menos no nível da administração federal) a formas individualizadas de interpor "reclamações" sobre os serviços prestados, como os setores de ouvidorias.

Há vários elementos que as estratégias de "empresariamento" trouxeram para o interior do Estado, como a "terceirização" e precarização do trabalho (vide o crescente número de estagiários desempenhando atividades antes restritas a funcionários "efetivos"), práticas discursivas orientadas

4 Luís Carlos Bresser Pereira foi um dos técnicos mais destacados e de atuação estratégica neste processo, uma vez que foi ministro nomeado para este fim. Ele dirigiu o Ministério da Administração e Reforma do Estado (MARE) durante o primeiro mandato do Presidente Fernando Henrique Cardoso, quando promoveu seminários e organizou livros sobre o tema. Entre suas produções, ver Bresser Pereira (1998). 
para os clientes, etc. Quanto ao aspecto tecnológico, o aperfeiçoamento dos sistemas estatais de informática têm permitido a comunicação entre as bases de dados corporativas e novas formas de organização e classificação dos cidadãos nesses bancos de dados. Também se têm criado novos dispositivos para ordenar as populações em indicadores estatísticos, quantificálas e regulá-las mais sofisticadamente. Atualmente, no caso de setores como a Previdência Social, verifica-se a existência da combinação entre tecnologias informáticas e estatísticas que potencializaram a capacidade de controle sobre a população e sobre os funcionários, tal como demonstra estudo que realizei (Benites, 2002).

Minard (2000) havia assinalado que, na França do Antigo Regime, o desenvolvimento da estatística industrial estava indissociado da produção de uma "vontade de saber" da administração do Estado. Hoje, esta racionalidade se reatualiza na articulação com as tecnologias informáticas produzindo não mais indivíduos modelados pelas técnicas disciplinares, mas "divíduos" modulados por técnicas de controle contínuo e permanente, tal como descreveu Deleuze (1992). Estes homens segmentados em várias partes (contribuintes, benefíciários, devedores e credores registrados diferentemente em múltiplos bancos de dados) revelam o lado produtivo das novas técnicas de poder. Estas mostram-se em total consonância com a lógica de administração imperial: integrar e depois dividir, para melhor controlar.

\section{Considerações finais}

Para um capitalismo englobante, que não possui mais um "fora", o campo estatal é um espaço a ser investido por sua lógica operatória. Este investimento significa "empresariá-lo", nos termos descritos por Veiga-Neto (2000, p. 198). Mas o capitalismo, assim como o Estado, não é uma entidade, uma substância. Em uma leitura foucaultiana, podemos pensar sua existência e reprodução associada ao desenvolvimento de saberes como a Eco- 
nomia, a Administração, etc., e à produção, apropriação e difusão de múltiplas técnicas de poder. A investigação de Dezalay e Garth (2000) demonstrou tal fenômeno. Nesse cenário, o trabalho no aparelho estatal pode constituir-se em uma categoria pertinente para se pensar as articulações entre dois jogos fundamentais nas estratégias de governamentalidade desde a modernidade: um, jogado na população, e outro, no indivíduo.

O jogo na população se tem realizado sob a lógica diferencial da administração imperial. No cenário da sociedade de controle, é interessante observar o aprofundamento e sofisticação dos instrumentos de controle, em alguns setores estatais, sobre aqueles que participam concretamente das práticas normalizadoras sobre a população: os trabalhadores no serviço público. Isso significa exercer controle sobre quem controla. Tal estratégia implica a renovação e sutilização das técnicas de regulação das populações.

Entretanto, essas táticas de governo não seriam eficazes sem a mobilização das subjetividades para esse objetivo. Aqui emerge o jogo no indivíduo. O circuito da governamentalização nos aparelhos administrativos se complementa com a produção da sujeição dos seus trabalhadores, um exemplo disso pode ser a "fabricação" do desejo de controle orientado para a administração do acesso aos direitos sociais, tal como demonstra Benites (2002). Tal "fabricação" se dá, por um lado, através das relações de saberpoder que envolvem a manipulação das "ciências de Estado", bem como as prescrições das condutas administrativas delas resultantes. O assujeitamento a esta racionalidade se dá a partir de uma zona em que as forças que compõem o trabalho burocrático enquanto conjunto de agenciamentos concretos que produz o sentido das formas de atuar, são vergadas para a constituição da relação consigo mesmas. Produzir-se como sujeito responsável, seguro, zeloso e prudente é uma forma possível de integrar-se à ordem social vigente no interior dos aparelhos administrativos do Estado.

Por outro lado, a multiplicidade de dados e as novas rotinas de controle sobre os cidadãos que os aplicativos e programas corporativos permitem 
acessar e manipular potencializam a produção da "vontade de saber" tramada em práticas de gestão de "ilegalidades". Esta tendência ilustra como o Estado, na condição de uma potência que se apropria dos recursos tecnológicos, invade o espaço da produção de desejos. Ele mesmo pode tornar-se um fluxo participante da subjetivação dos trabalhadores no serviço público fazendo com que o "prazer da subjetivação" coincida com o "prazer do controle", fenômeno recorrente na contemporaneidade, tal como afirma Cardoso Jr (2002, p. 196).

O caminho proposto neste ensaio foi o da análise das transformações mais amplas da sociedade e suas ressonâncias no Estado. Neste sentido, compartilhamos a idéia de

(...) que, para Foucault, por exemplo, o Estado era uma condensação de relações microfísicas de poder disciplinar. Nas sociedades de controle, parece que o próprio Estado tornou-se molecular para difundir-se no espaço da subjetivação, ele tornou-se emissor de fluxos ou é um fluxo (id., p. 196).

Se a sociedade de controle é uma sociedade de comunicação rápida e instantânea, como afirmou Deleuze (1992), as resistências podem emergir justamente deste terreno. O exercício do contrapoder pode realizar-se através de constituição de redes de trocas de informação e de sociabilidade que se apropriem dos fluxos tecnológicos de comunicação (a internet é um exemplo) para divulgar e promover novos pensamentos e modos de vida. Entretanto é preciso estar atento, pois:

O problema das sociedades de controle, (...), não é exatamente que os processos de subjetivação se apoiem, sobre fluxos tecnológicos, o problema é como esses e outros fluxos são enfeixados pelo controle.

O problema da sociedade de controle, em poucas palavras, é que esses fluxos são constantemente modula- 
dos em função de uma axiomática, ensina Deleuze, permitindo que potências como o Estado, a Comunicação, a Ciência, a Psicanálise, participem dos processos de subjetivação a ponto de ditar-Ihes os ritmos (Cardoso Jr, 2002, p. 195).

Talvez, uma possibilidade de superar esta relação Estado-sociedade se encontre na potencialidade do trabalho imaterial em criar outros laços de sociabilidade entre segmentos da multidão ${ }^{5}$ (trabalhadores "imateriais" no serviço público e as populações moduladas pela axiomática do controle, podem constituir uma articulação possível). Certamente, tais laços de sociabilidade teriam de organizar territórios coletivos de resistência para além do espaço estatal. Na articulação de uma dinâmica de luta pela produção de direitos que transcenda as práticas reguladoras estatais, encontram-se as possibilidades da constituição de linhas de fuga ao Império. Através dessas linhas de fuga, abrem-se caminhos para um biopoder construído de baixo para cima, recompondo espaços de resistências e de constituição de novos modos de vida e de produção de subjetividades para além do molde e da modulação que produziram a forma biopolítica da população.

\footnotetext{
1 A "multidão", segundo Hardt e Negri (2001), é a forma social contemporânea de um sujeito capaz de produzir um poder constituinte. A multidão se apresenta pela multiplicidade da sua composição em contraposição à unidade do povo. A referida multiplicidade indica que não há mais um confronto central (patrões versus proletários) que organiza todas as demais lutas sociais. A rede de microconflitualidades da sociedade de controle mundial expressa a tensão da relação Império-multidão em vários pontos estratégicos. O aparato de captura imperial sempre busca controlar a potência biopolítica da multidão.
} 


\section{Referências:}

BADIE, Bertrand; HERMET, Guy. Política Comparada. México: Fondo de Cultura Economica, 1993.

BARBOSA, Lívia. Igualdade e Meritocracia: a ética do desempenho nas sociedades modernas. 2ª ed. Rio de Janeiro: Ed. FGV, 1999.

BENITES, Luiz Felipe Rocha. Controle, Governo e Subjetividade: um estudo sobre o trabalho na Previdência Social no RS. 2002. 150 f. Dissertação (Mestrado em Sociologia) - Instituto de Filosofia e Ciências Humanas, Universidade Federal do Rio Grande do Sul, Porto Alegre.

BORON, Atílio Alberto. Império e Imperialismo: uma leitura crítica de Michael Hardt e Antonio Negri. Buenos Aires: Clacso, 2002.

BOURDIEU, Pierre. Razões Práticas: sobre a teoria da ação. Campinas, SP: Papirus, 1996.

BOURDIEU, Pierre, CHRISTIN, Olivier; WILL, Pierre-Étienne. Sur la science de I'État. Actes de la Recherche en Sciences Sociales, Paris, no 133, p. 3-9, jun. 2000.

BRESSER PEREIRA, Luiz Carlos. A reforma do Estado dos anos 90: lógica e mecanismos de controle. Cadernos do MARE da Reforma do Estado, n 1/98. Disponível em: < http://www.mare.gov.br> Acesso em: 15 nov.1998.

CARDOSO JR, Hélio Rebello. Foucault e Deleuze em co-participação no plano conceitual. In: RAGO, Margareth et al. (orgs.). Imagens de Foucault e Deleuze: ressonâncias nietzschianas. Rio de Janeiro: DP\&A, 2002.

DELEUZE, Gilles. Foucault. São Paulo: Brasiliense, 1988.

DELEUZE, Gilles. Post Scriptum sobre as sociedades de controle. In:

Conversações. Rio de Janeiro: Ed. 34, 1992.

DEZALAY, Yves; GARTH, Bryant. A dolarização do conhecimento técnico profissional e do Estado: processos transnacionais e questões de legitimação na transformação do Estado, 1960-2000. Revista Brasileira de Ciências Sociais, São Paulo, v. 15, n. 43, p. 163-176, jun. 2000. 
ELIAS, Norbert. O Processo Civilizador, v. 2. Rio de Janeiro: Zahar, 1993.

FOUCAULT, Michel. Tecnologías del yo y otros textos afines. Barcelona: Paidós, 1990.

FOUCAULT, Michel. O Sujeito e o Poder. In: DREYFUS, Hubert; RABINOW, Paul. Michel Foucault: uma trajetória filosófica para além do estruturalismo e da hermenêutica. Rio de Janeiro: Forense Universitária, 1995.

FOUCAULT, Michel. Resumo de Cursos do Collège de France (1970-1982). Rio de Janeiro: Zahar, 1997.

FOUCAULT, Michel. Em Defesa da Sociedade: curso no College de France (19751976). São Paulo: Martins Fontes, 1999.

FOUCAULT, Michel. Microfísica do Poder. 15 ed. Rio de Janeiro: Graal, 2000.

GENET, Jean-Pierre. La Genèse de l'État Moderne: les enjeux d'un programme de recherche. Actes de la Recherche en Sciences Sociales, Paris, no 118, jun. 1997.

HARDT, Michael. O Hibridismo do Império. Lugar Comum, Rio de Janeiro, $\mathrm{n} \cong$ 1, p. 55-69, mar. 1997.

HARDT, Michael. A sociedade mundial de controle. In: ALLIEZ, Eric (org.). Gilles Deleuze: uma vida filosófica. São Paulo: Ed. 34, 2000.

HARDT, Michael; NEGRI, Antonio. Império. Rio de Janeiro: Record, 2001.

JOBERT, Bruno. Les Politiques Sociais et Sanitaires. In: GRAWITZ, M.; LECA, J. (orgs.). Traité de Science Politique. Paris: PUF, 1985.

LAMOROUX, Christian. Qualification des hommes e procédures administratives. Actes de la Recherche en Sciences Sociales, Paris, no 133, p. 26-31, jun. 2000.

LAZZARATO, Maurizio; NEGRI, Antonio. Trabalho imaterial e subjetividade. In: Trabalho Imaterial: formas de vida e produção de subjetividade. Rio de Janeiro: Ed. DP\&A, 2001.

MACEDO Jr, Ronaldo Porto. Foucault: o poder e o direito. Tempo Social, Revista Sociologia USP, São Paulo, v. 2, n.1, p. 155-176,1990. 
MINARD, Phillipe. Volonté de Savoir et Emprise d'État: aux origines de la statistique industrielle dans la France d'Ancien Regime. Actes de la Recherche en Sciences Sociales, Paris, no 133, p. 63- 71, jun. 2000.

PETERS, B. Guy. La Política de la Burocracia. México: Fondo de Cultura Economica, 1999.

VEIGA-NETO, Alfredo. Educação e Governamentalidade Neoliberal: novos dispositivos, novas subjetividades. In: PORTOCARRERO, Vera; CASTELO BRANCO, Guilherme. (orgs.). Retratos de Foucault. Rio de Janeiro: Ed. Nau, 2000.

VEIGA-NETO, Alfredo. Coisas do governo... In: RAGO, Margareth et al. (orgs.). Imagens de Foucault e Deleuze: ressonâncias nietzschianas. Rio de Janeiro: DP\&A, 2002.

WEBER, Max. Economia y Sociedad, v. 2. México: Fondo de cultura Económica, 1969.

Recebido: 15/09/2003

Aceite final: 14/01/2004 


\section{Resumo}

Este ensaio analisa o processo de "governamentalização" do Estado e as implicações desse processo para a sua própria continuidade. Nutrindo-se de trabalhos genealógicos e estudos contemporâneos, procura-se cartografar alguns caminhos pelos quais os mecanismos de controle e regulação das populações estão sendo recriados e reorganizados, renovando a capacidade normalizadora do campo estatal. A análise aponta que o exercício do "governamento" contemporâneo avança no território do trabalho imaterial no serviço público ao articular o uso de novas tecnologias telemáticas com a produção de subjetividades "desejantes" de controle.

Palavras-chave: Transformações do Estado, gorvernamentalidade, trabalho imaterial, sociedade de controle, produção de subjetividade. 